\section{Commentary: Locally advanced thymoma resection: See 100, do 1, teach 1}

\author{
Stephen R. Hazelrigg, MD
}

In this issue of JTCVS Techniques, Wang and colleagues ${ }^{1}$ present a case report that includes a video of a thymectomy performed for a stage III thymoma involving the innominate vein. The video is excellent, and as you watch it you feel very comfortable with the procedure, in that it moves forward in a very safe fashion.

Minimally invasive surgery (MIS) techniques for thymectomy have been evolving for quite a long time, and there is now ample literature suggesting that there are similar oncologic results for early-stage thymoma. Studies also have suggested that minimally invasive thymectomy can reduce surgical trauma, improve postoperative recovery, decreased hospital length of stay, and decreased overall pain. $^{2,3}$ The questions obviously come when we look at more locally advanced thymomas. The unknown in all MIS techniques is how far can we safely push the envelope and still get good outcomes.

Yang and colleagues ${ }^{4}$ conducted a database evaluation of $>1200$ patients treated surgically for stage I through III thymomas, including approximately $25 \%$ using MIS approaches. Once again, long-term results showed no significant difference in oncologic outcomes. Specifically, there were similar findings with regard to margins, 5-year survival rates, and mortality. The advantages included a slight decrease in the length of stay. Overall, there are several patients considered higher risk in which one would be hesitant to use MIS approaches, including those with locally

\footnotetext{
From the Southern Illinois University School of Medicine, Springfield, Ill. Disclosures: The author reported no conflicts of interest.

The Journal policy requires editors and reviewers to disclose conflicts of interest and to decline handling or reviewing manuscripts for which they may have a conflict of interest. The editors and reviewers of this article have no conflicts of interest.

Received for publication April 22, 2021; revisions received April 22, 2021; accepted for publication April 22, 2021; available ahead of print April 27, 2021.

Address for reprints: Stephen R. Hazelrigg, MD, Southern Illinois University School of Medicine, $701 \mathrm{~N}$ 1st St, Room D252, Springfield, IL 62702 (E-mail: shazelrigg@siumed.edu).

JTCVS Techniques 2021;8:211-2

2666-2507

Copyright (c) 2021 The Author(s). Published by Elsevier Inc. on behalf of The American Association for Thoracic Surgery. This is an open access article under the CC BY-NC-ND license (http://creativecommons.org/licenses/by-nc-nd/4.0/).

https://doi.org/10.1016/j.xjtc.2021.04.026
}

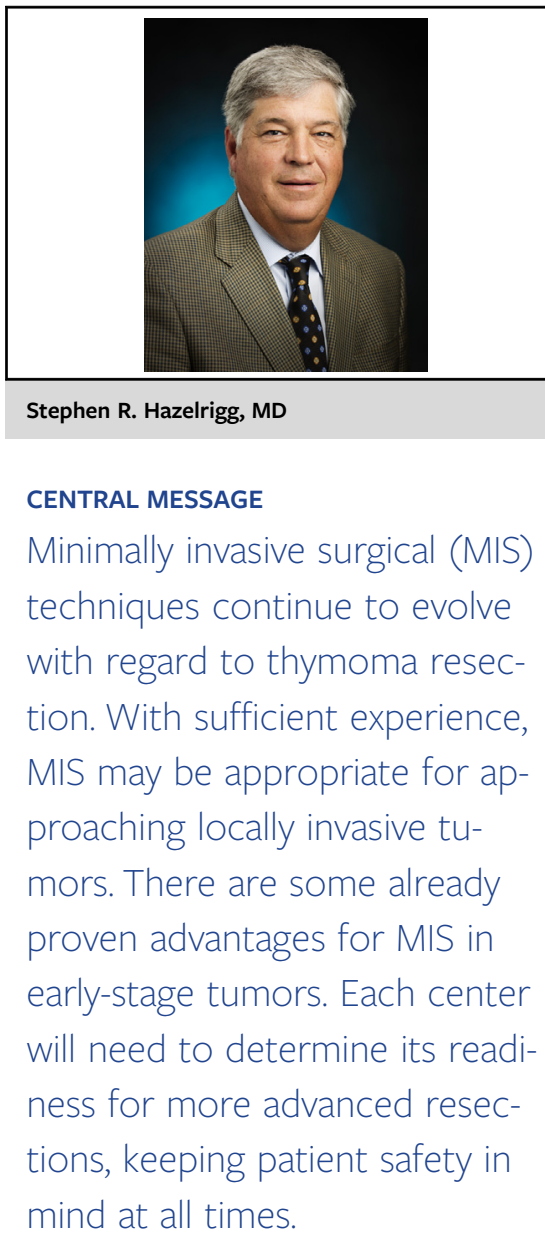

advanced tumors, preoperative induction therapy treatment, and a prior history of mediastinal surgery. Obviously, this video shows a case with a safe resection of a locally advanced tumor. This is not the first report of such a procedure.

This sort of progression is what one might expect with the adoption of MIS techniques and has occurred in all areas where minimally invasive techniques have been used. The question always becomes how far we can push the envelope. Clearly this needs to be guided carefully based on experience, MIS skills, and instrumentation. The authors have performed $>100$ minimally invasive thymectomies and thus have worked their way through a significant learning curve that make them comfortable with the procedure. It is difficult to say what the standard should be across the board for all thoracic surgeons and who should and should not approach these more advanced cases.

The other area of comment is the particular technique used here, with the subxiphoid approach and the hook 
retraction of the sternum. Based on the video, this technique provides excellent exposure and clearly works very well. Whether there is any significant advantage of this approach over a thoracoscopic or robotic type of an approach seems unclear.

In the end, this is an excellent video, the procedure appears to be very safe, and the outcome appears to be good. We are seeing an increasing use of MIS techniques and approaches for locally advanced tumors. I think this a natural and expected progression. It simply requires careful consideration by each surgical team to decide how best to approach it. As always, surgical safety is of paramount importance and cannot be compromised.

\section{References}

1. Wang X, Aramini B, Xu H, Fan J. Thymectomy with angioplasty through a thoracoscopic subxiphoid approach with double elevation of the sternum in Masaoka stage III thymoma. J Thorac Cardiovasc Surg Tech. 2021;8:208-10.

2. Fang W, Gu Z, Chen K. Minimally invasive surgery in thymic malignances. Zhongguo Fei Ai Za Zhi. 2018;21:269-72.

3. Fang W, Feng J, Ji C, Xiang Y. Minimally invasive thymectomy for locally advanced recurrent thymoma. J Vis Surg. 2016;2:58.

4. Yang C-FJ, Hurd J, Shah SA, Liou D, Wang H, Backhus LM, et al. A national analysis of open versus minimally invasive thymectomy for stage I to III thymoma. $J$ Thorac Cardiovasc Surg. 2020;160:555-67.e15. 